\title{
Genetic diversity and population structure of Stipa bungeana, an endemic species in Loess Plateau of China, revealed using combined ISSR and SRAP markers
}

\author{
J. Yu ${ }^{1}$, Z.B. Jing ${ }^{2}$ and J.M. Cheng ${ }^{1,2}$ \\ ${ }^{1}$ College of Natural Resources and Environment, Northwest A\&F University, \\ Yangling, Shaanxi, China \\ ${ }^{2}$ College of Animal Science and Technology, Northwest A\&F University, \\ Yangling, Shaanxi, China \\ Corresponding author: J.M. Cheng \\ E-mail: gyzcjm@ms.iswc.ac.cn
}

Genet. Mol. Res. 13 (1): 1097-1108 (2014)

Received January 18, 2013

Accepted July 3, 2013

Published February 20, 2014

DOI http://dx.doi.org/10.4238/2014.February.20.11

\begin{abstract}
Sequence-related amplified polymorphism (SRAP) and inter-simple sequence repeat (ISSR) markers were used to assess the genetic diversity within and among 15 natural populations of Stipa bungeana from the Loess Plateau of China. Using 15 SRAP primers, 504 $(99.80 \%)$ polymorphic loci were detected, and 372 polymorphic loci $(96.12 \%)$ were identified using 15 ISSR primers. At the species level, the $S$. bungeana populations showed relatively low levels of genetic diversity $\left(H_{\mathrm{E}}=0.2017\right.$ for SRAP; $H_{\mathrm{E}}=0.2066$ for ISSR). The results of analysis of molecular variance indicated that genetic variation within populations (42.02\% for SRAP and $38.40 \%$ for ISSR) is lower than that among populations (57.98\% for SRAP and $61.60 \%$ for ISSR). The genetic distance was significantly correlated with geographical distance by the Mantel test $(r=0.3978, P=0.002)$. Our results demonstrated that both SRAP and ISSR markers are effective and reliable for assessing
\end{abstract}


the genetic diversity of $S$. bungeana. In addition, these data inform conservation and breeding strategies for S. bungeana.

Key words: Stipa bungeana; SRAP; ISSR; Genetic diversity

\section{INTRODUCTION}

Stipa bungeana Trin. is a perennial grass that grows mainly in western China, including Tibet, Gansu, Ningxia, Xinjiang, Qinghai, Shaanxi, Shanxi, and Inner Mongolia. It grows with typical vegetative propagation by repeatedly producing tiller ramets from the shoot base, and is considered as a dominant and constructive species in the typical steppe of the Loess Plateau (Cheng et al., 2011). In addition, S. bungeana is also an important pasture species due to its high level of nutrients and excellent drought tolerance. To date, studies on S. bungeana have focused on its biological traits and ecological significance, while information on its genetic diversity and population structure has not yet been reported. Analyses of genetic diversity and structure at the intraspecific level are particularly important for species conservation, exploration of plant genetic resources, and future breeding programs of wild plants (Hamrick and Godt, 1996).

Molecular markers are effective tools for revealing genetic diversity and population structure. Among the various DNA marker-assisted techniques, inter-sequence simple repeat (ISSR), a newly developed modification of the simple sequence repeat-based marker system, is useful for detecting genetic polymorphisms among accessions by generating a large number of markers that target multiple microsatellite loci distributed across the genome (Godwin et al., 1997). Sequence-related amplified polymorphism (SRAP), another proven molecular marker technique, is a simple and reliable polymerase chain reaction (PCR)-based marker system that is designed to detect mostly coding sequence polymorphisms ( $\mathrm{Li}$ and Quiros, 2001). Combinations of the two types of marker systems have been successfully used to analyze genetic diversity and population structure in some plant species (Ferriol et al., 2003; Shao et al., 2010; Song et al., 2010; Wu et al., 2010b). To date, the genetic diversities of certain plants belonging to the Stipa genus have been reported, including Stipa grandis, Stipa purpurea, and Stipa krylovii (Wang et al., 2006; Zhao et al., 2006, 2008; Liu et al., 2009; Wu et al., 2010a).

In the present study, a combination of ISSR and SRAP procedures were used to assess the genetic diversity within and among 15 S. bungeana populations from the Loess Plateau of China. The objectives of this study were to: 1) investigate the level of genetic diversity in $S$. bungeana populations, 2) analyze the relationship between genetic diversity and environmental factors, and 3) provide information for the development of conservation practices for S. bungeana.

\section{MATERIAL AND METHODS}

\section{Study area and population sampling}

In August 2010, 15 sampling sites (A1 to A15) were selected in the semi-arid area of the Loess Plateau of China, which is located between northern latitudes $33^{\circ} 48^{\prime}$ to $38^{\circ} 06^{\prime}$ and eastern longitudes $105^{\circ} 01^{\prime}$ to $109^{\circ} 45^{\prime}$. These sites included Ningxia, Inner Mongolia, Gansu, 
and Shaanxi Provinces (Figure 1; Table 1). Twenty individuals were sampled randomly from each $S$. bungeana population, and the distance between the plants was at least $10 \mathrm{~m}$ in the same population to avoid collecting ramets from the same genet. Young and fresh leaves were collected from S. bungeana individuals and immediately stored on silica gel for transportation to the laboratory for DNA extraction.

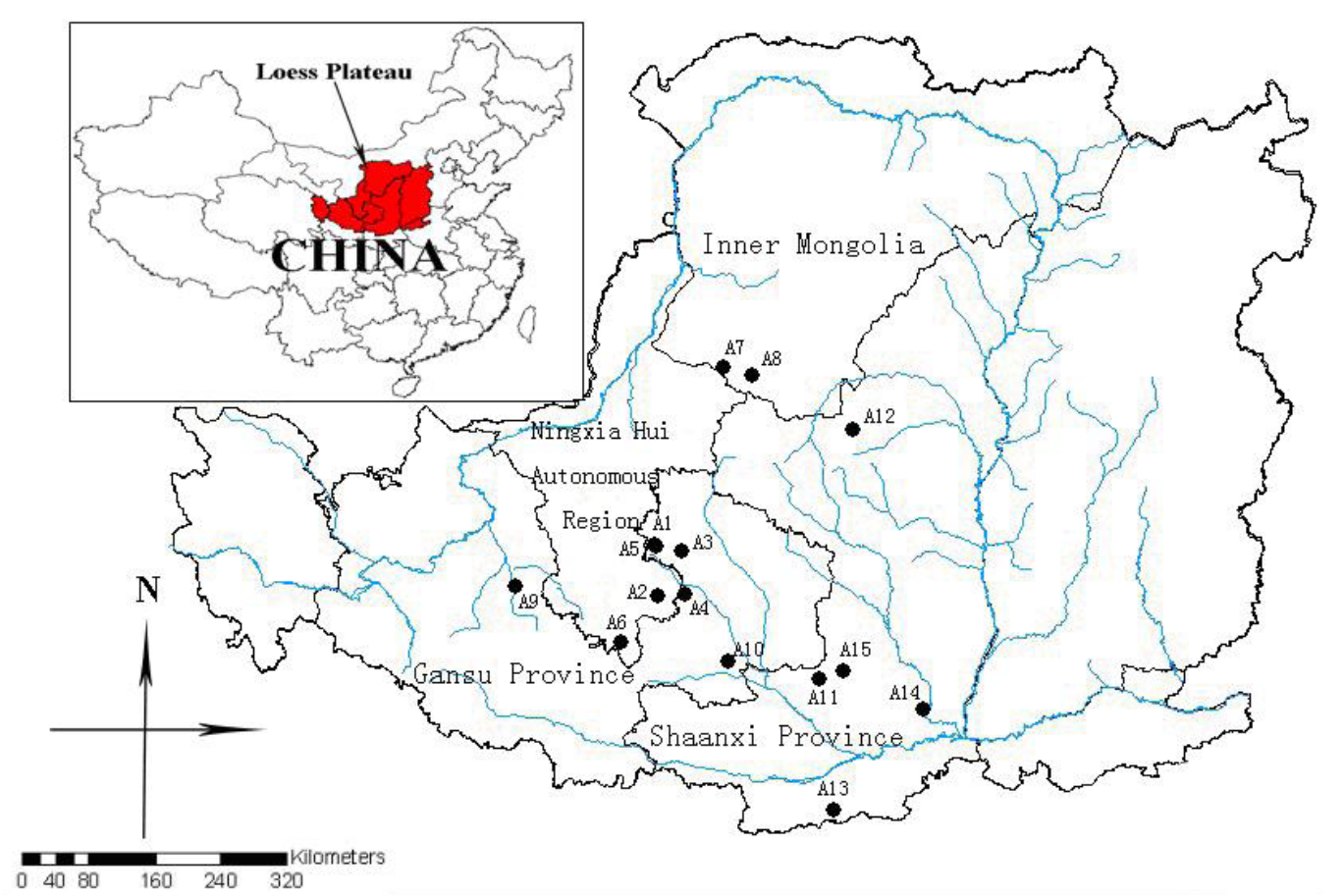

Figure 1. Map of research sites in the Loess Plateau of China.

Table 1. Locations and the habitat characteristics of sampling sites.

\begin{tabular}{|c|c|c|c|c|c|}
\hline Location & Code & Altitude (m) & Longitude & Latitude & Habitat \\
\hline Nanshan, Yunwu Mountain, Ningxia & A1 & 2049 & $106^{\circ} 37^{\prime}$ & $36^{\circ} 25^{\prime}$ & Typical Steppe \\
\hline Xiji, Ningxia & A2 & 2081 & $106^{\circ} 40^{\prime}$ & $35^{\circ} 56^{\prime}$ & Typical Steppe \\
\hline Huangmao Mountain, Ningxia & A3 & 1772 & $106^{\circ} 56^{\prime}$ & $36^{\circ} 21^{\prime}$ & Typical Steppe \\
\hline Hechuan, Ningxia & A4 & 1650 & $106^{\circ} 59^{\prime}$ & $35^{\circ} 57^{\prime}$ & Typical Steppe \\
\hline Deteriorated grassland, Yunwu Mountain, Ningxia & A5 & 1980 & $106^{\circ} 37^{\prime}$ & $36^{\circ} 27^{\prime}$ & Typical Steppe \\
\hline Liupan Mountain, Ningxia & A6 & 1760 & $106^{\circ} 16^{\prime}$ & $35^{\circ} 29^{\prime}$ & Typical Steppe \\
\hline Chengchuan, Inner-Mongolia & A7 & 1364 & $107^{\circ} 23^{\prime}$ & $38^{\circ} 06^{\prime}$ & Desert Steppe \\
\hline Machangjie, Inner-Mongolia & A8 & 1354 & $107^{\circ} 43^{\prime}$ & $38^{\circ} 02^{\prime}$ & Desert Steppe \\
\hline Huining, Gansu & A9 & 1726 & $105^{\circ} 01^{\prime}$ & $35^{\circ} 58^{\prime}$ & Typical Steppe \\
\hline Jingchuan, Gansu & $\mathrm{A} 10$ & 1305 & $107^{\circ} 31^{\prime}$ & $35^{\circ} 19^{\prime}$ & Forest Steppe \\
\hline Tong Chuan, Shaanxi & A11 & 1200 & $108^{\circ} 34^{\prime}$ & $35^{\circ} 10^{\prime}$ & Forest Steppe \\
\hline Jing Bian, Shaanxi & $\mathrm{A} 12$ & 1390 & $108^{\circ} 56^{\prime}$ & $37^{\circ} 32^{\prime}$ & Desert Steppe \\
\hline Huxian, Shaanxi & A13 & 450 & $108^{\circ} 44^{\prime}$ & $33^{\circ} 48^{\prime}$ & Forest Steppe \\
\hline Pucheng, Shaanxi & A14 & 430 & $109^{\circ} 45^{\prime}$ & $34^{\circ} 53^{\prime}$ & Forest Steppe \\
\hline Binxian, Shaanxi & A 15 & 1161 & $108^{\circ} 50^{\prime}$ & $35^{\circ} 15^{\prime}$ & Forest Steppe \\
\hline
\end{tabular}




\section{Genomic DNA extraction}

Genomic DNA was extracted from young leaves by the modified cetyltrimethylammonium bromide method (Zhao et al., 2006). DNA concentration and quality were evaluated by UV-VIS spectrophotometry and on $0.8 \%(\mathrm{w} / \mathrm{v})$ agarose gels, respectively. Samples were diluted to $20 \mathrm{ng} / \mu \mathrm{L}$ and stored at $-20^{\circ} \mathrm{C}$ for PCR analysis.

\section{SRAP analysis}

A set of 38 primers, including 17 forward primers and 21 reverse primers, were synthesized by the Beijing Aoke Biological Engineering Technology Co., Ltd., as reported in previous studies (Ferriol et al., 2003; Budak et al., 2004; Guo and Luo, 2006). Four individual plants from different populations were used for primer screening. Finally, 15 primer combinations (Table 2) were selected for subsequent studies, based on clarity, reproducibility of amplified bands, and high rates of polymorphism. For PCR amplification, SRAP amplifications were performed in $20-\mu \mathrm{L}$ reaction volumes containing $3 \mu \mathrm{L} 20 \mathrm{ng} / \mu \mathrm{L}$ DNA, $0.2 \mu \mathrm{L}$ Taq DNA polymerase (TaKaRa Biotechnology, Dalian, China), $1.4 \mu \mathrm{L} 2.5 \mathrm{mM}$ dNTPs, $3 \mu \mathrm{L} 10$ $\mu \mathrm{M}$ primer, $2 \mu \mathrm{L} 25 \mathrm{mM} \mathrm{Mg}^{2+}, 2.5 \mu \mathrm{L} 10 \mathrm{X}$ buffer, and $7.9 \mu \mathrm{L} \mathrm{ddH}_{2} \mathrm{O}$. PCR amplification was carried out on an Eppendorf PCR instrument and comprised the following profile: $5 \mathrm{~min}$ of denaturing at $94^{\circ} \mathrm{C}$, five cycles of three steps: $1 \mathrm{~min}$ of denaturing at $94^{\circ} \mathrm{C}, 1 \mathrm{~min}$ of annealing at $35^{\circ} \mathrm{C}$, and $1 \mathrm{~min}$ of extension at $72^{\circ} \mathrm{C}$. In the following 35 cycles, the annealing temperature was increased to $50^{\circ} \mathrm{C}$, with a final elongation step of $10 \mathrm{~min}$ at $72^{\circ} \mathrm{C}$. Amplified products were electrophoresed on $6 \%$ denaturing polyacrylamide gel, which was silver stained and photographed.

\begin{tabular}{|c|c|c|c|}
\hline Primer & Sequence $\left(5^{\prime}-3^{\prime}\right)$ & Primer & Sequence $\left(5^{\prime}-3^{\prime}\right)$ \\
\hline $\mathrm{Me} 1+\mathrm{Em} 2$ & $\begin{array}{l}\text { TGA GTC CAA ACC GGATA } \\
\text { GAC TGC GTA CGA ATT TGC }\end{array}$ & Me12+Em8 & $\begin{array}{l}\text { TGA GTC CAA ACC GGAGA } \\
\text { GAC TGC GTA CGA ATT CAC }\end{array}$ \\
\hline $\mathrm{Me} 1+\mathrm{Em} 4$ & $\begin{array}{l}\text { TGA GTC CAA ACC GGATA } \\
\text { GAC TGC GTA CGA ATT TGA }\end{array}$ & $\mathrm{Me} 12+\mathrm{Em} 14$ & $\begin{array}{l}\text { TGA GTC CAA ACC GGAGA } \\
\text { GAC TGC GTA CGA ATT CTT }\end{array}$ \\
\hline Me1+Em17 & $\begin{array}{l}\text { TGA GTC CAA ACC GGATA } \\
\text { GACTGCGTACG AATT GAG }\end{array}$ & $\mathrm{Me} 13+\mathrm{Em} 12$ & $\begin{array}{l}\text { TGA GTC CAA ACC GGAAG } \\
\text { GAC TGC GTA CGA ATT CTC }\end{array}$ \\
\hline Me4+Em1 & $\begin{array}{l}\text { TGA GTC CAA ACC GGACC } \\
\text { GAC TGC GTA CGA ATT AAT }\end{array}$ & Me13+Em14 & $\begin{array}{l}\text { TGA GTC CAA ACC GGAAG } \\
\text { GAC TGC GTA CGA ATT CTT }\end{array}$ \\
\hline Me5+Em4 & $\begin{array}{l}\text { TGA GTC CAA ACC GGAAG } \\
\text { GAC TGC GTA CGA ATT TGA }\end{array}$ & ME6-X+Em7 & $\begin{array}{l}\text { TGA GTC CTT TCC GG TAA } \\
\text { GAC TGC GTA CGA ATT CAA }\end{array}$ \\
\hline Me5+Em11 & $\begin{array}{l}\text { TGA GTC CAA ACC GGAAG } \\
\text { GAC TGC GTA CGA ATT CTA }\end{array}$ & ME6-X+Em8 & $\begin{array}{l}\text { TGA GTC CTT TCC GG TAA } \\
\text { GAC TGC GTA CGA ATT CAC }\end{array}$ \\
\hline Me8+Em19 & $\begin{array}{l}\text { TGA GTC CAA ACC GGACT } \\
\text { GACTGCGTACG AATT TCA }\end{array}$ & ME6-X+EM3-X & $\begin{array}{l}\text { TGA GTC CTT TCC GG TAA } \\
\text { GAC TGC GTA CGA ATT CGA }\end{array}$ \\
\hline Me11+Em9 & $\begin{array}{l}\text { TGA GTC CAA ACC GGAAC } \\
\text { GACTGCGTACG AATT TCA }\end{array}$ & & \\
\hline
\end{tabular}




\section{ISSR analysis}

According to the primer sequences published by the University of British Columbia, 96 ISSR primer sequences were synthesized by Beijing Aoke Biological Technology Co., Ltd. Four individual plants from each population were used for primer screening. Finally, 15 primers (Table 3) were selected for ISSR analysis. The PCR amplification comprised a total volume of $20 \mu \mathrm{L}$ containing $3 \mu \mathrm{L} 20 \mathrm{ng} / \mu \mathrm{L}$ DNA, $0.2 \mu \mathrm{L}$ Taq DNA polymerase (TaKaRa Biotechnology), $1.4 \mu \mathrm{L} 2.5 \mathrm{mM}$ dNTPs, $3 \mu \mathrm{L} 10 \mu \mathrm{M}$ primer, $1.4 \mu \mathrm{L} 25 \mathrm{mM} \mathrm{Mg}^{2+}, 2.5 \mu \mathrm{L} 10 \mathrm{X}$ buffer, and $8.3 \mu \mathrm{LddH}_{2} \mathrm{O}$. PCR amplification was carried out on the Eppendorf PCR instrument and the reaction program comprised an initial $5 \mathrm{~min}$ at $94^{\circ} \mathrm{C} ; 35$ cycles of $45 \mathrm{~s}$ at $94^{\circ} \mathrm{C}, 45 \mathrm{~s}$ annealing at $50^{\circ} \mathrm{C}$ (varying for different primers), and a 90 -s extension at $72^{\circ} \mathrm{C}$; ending with a final extension of $5 \mathrm{~min}$ at $72^{\circ} \mathrm{C}$ and storage at $4^{\circ} \mathrm{C}$. Amplified products were electrophoresed on $6 \%$ denaturing polyacrylamide gel, which was silver stained and photographed.

\begin{tabular}{|c|c|c|c|c|c|}
\hline Primer & Sequence $\left(5^{\prime}-3^{\prime}\right)$ & Optimal annealing temperature $\left({ }^{\circ} \mathrm{C}\right)$ & Primer & Sequence $\left(5^{\prime}-3^{\prime}\right)$ & Optimal annealing temperature $\left({ }^{\circ} \mathrm{C}\right)$ \\
\hline UBC806 & $(\mathrm{TA})_{8} \mathrm{G}$ & 41.5 & UBC 840 & $(\mathrm{GA})_{8} \mathrm{YT}$ & 54.1 \\
\hline UBC813 & $(\mathrm{CT})_{8} \mathrm{~T}$ & 48.4 & UBC864 & $(\mathrm{ATG})_{5}$ & 46.7 \\
\hline UBC814 & $(\mathrm{CT})_{8}^{8} \mathrm{~A}$ & 50.0 & UBC868 & $(\mathrm{GAA})_{5}^{5}$ & 42.6 \\
\hline UBC 820 & $(\mathrm{GT})_{8} \mathrm{C}$ & 57.7 & UBC 880 & $\left(\mathrm{GGAGA}_{3}\right)_{3}$ & 51.0 \\
\hline UBC822 & $(\mathrm{TC})_{8}^{8} \mathrm{~A}$ & 55.7 & UBC 886 & $\operatorname{VDV}(\mathrm{CT})_{7}^{3}$ & 57.7 \\
\hline UBC823 & $(\mathrm{TC})_{8}^{8} \mathrm{C}$ & 57.7 & UBC 887 & $\mathrm{VDV}(\mathrm{TC})_{7}$ & 54.5 \\
\hline UBC827 & $(\mathrm{AC})_{8}^{8} \mathrm{G}$ & 56.4 & UBC891 & $\mathrm{HVH}(\mathrm{TG})_{7}$ & 47.1 \\
\hline UBC834 & $(\mathrm{AG})_{8} \mathrm{YT}$ & 56.0 & & & \\
\hline
\end{tabular}

\section{Data analysis}

Clear and reproducible bands between 200-2000 bp were selected for statistical analysis. Amplified fragments were scored as 1 for presence or 0 for absence. The DCFA1.1 program was used to build the original document for data analysis (Zhang and Song, 2002). POPGENE1.32 (Yeh and Boyle, 1997) was used to calculate the following genetic diversity parameters: the percentage of polymorphic bands (PPB), Shannon's information index (I), Nei's gene diversity $(H)$, the effective number of alleles $\left(N_{\mathrm{E}}\right)$ and observed number of alleles $\left(N_{\mathrm{A}}\right)$, genetic differentiation $\left(G_{\mathrm{ST}}\right)$, and Nei's genetic distance. The average level of gene flow $\left(N_{\mathrm{M}}\right)$ among populations was indirectly calculated using the formula: $N_{\mathrm{M}}=0.5\left(1-G_{\mathrm{ST}}\right) / G_{\mathrm{ST}}$ (McDermott and McDonald, 1993). The unweighted pair-group method with arithmetic averages (UPGMA) dendrograms were constructed based on the matrix of Nei's genetic distances using NTSYS-pc (Rohlf, 2000). In addition, analysis of molecular variance (AMOVA) was used to estimate the coefficient of genetic variation among and within populations (Excoffier et al., 1992). The variance components were tested statistically by nonparametric randomization tests using 1000 permutations. Pearson's correlation analysis was used to detect correlations between genetic diversity parameters and environmental factors, including altitude, longitude, latitude, annual mean temperature, and annual mean precipitation. All of these analyses were performed with SPSS11.0 (SPSS 2001). Finally, the relationship between genetic distance and corresponding geographical distance among all populations was tested with the Mantel test (Mantel, 1967). 


\section{RESULTS}

\section{Genetic diversity detected by SRAP and ISSR}

For the 300 individuals, the 15 selected SRAP primers generated 504 polymorphic bands, and the PPB varied from 17.82 (A7) to $45.54 \%$ (A5), with a mean of $29.12 \%$. The $H$ value ranged from 0.0485 in the A7 population to 0.1131 in the A5 population, with a mean of 0.0848 . The $I$ values were between 0.0755 (A7) and 0.1748 (A5), with a mean of 0.1299 . At the species level, the $H$ and $I$ values were 0.2017 and 0.3273 , respectively (Table 4).

\begin{tabular}{|c|c|c|c|c|c|c|c|c|}
\hline \multirow[t]{2}{*}{ Groups } & \multicolumn{2}{|c|}{ Polymorphic bands } & \multicolumn{2}{|c|}{ Percentage of polymorphic bands } & \multicolumn{2}{|c|}{ Nei's gene diversity } & \multicolumn{2}{|c|}{ Shannon's information index } \\
\hline & SRAP & ISSR & SRAP & ISSR & SRAP & ISSR & SRAP & ISSR \\
\hline A1 & 137 & 109 & 27.13 & 18.17 & 0.0778 & 0.0800 & 0.1198 & 0.1240 \\
\hline A2 & 173 & 202 & 34.26 & 52.20 & 0.1011 & 0.1511 & 0.1550 & 0.2322 \\
\hline A3 & 116 & 136 & 34.85 & 35.14 & 0.0989 & 0.1026 & 0.1526 & 0.1571 \\
\hline A4 & 171 & 134 & 33.86 & 34.63 & 0.0870 & 0.0989 & 0.1364 & 0.1530 \\
\hline A5 & 230 & 157 & 45.54 & 40.57 & 0.1131 & 0.1108 & 0.1748 & 0.1723 \\
\hline A6 & 161 & 101 & 31.88 & 26.10 & 0.0826 & 0.0704 & 0.1285 & 0.1093 \\
\hline A7 & 90 & 101 & 17.82 & 26.10 & 0.0485 & 0.0834 & 0.0755 & 0.1260 \\
\hline A8 & 116 & 74 & 22.97 & 19.12 & 0.0725 & 0.0588 & 0.1092 & 0.0895 \\
\hline A9 & 141 & 105 & 27.92 & 27.13 & 0.0864 & 0.0878 & 0.1308 & 0.1329 \\
\hline A10 & 135 & 84 & 26.73 & 21.71 & 0.0881 & 0.0613 & 0.1321 & 0.0940 \\
\hline A11 & 140 & 87 & 27.72 & 22.48 & 0.0860 & 0.0646 & 0.1310 & 0.0989 \\
\hline A12 & 113 & 52 & 22.38 & 12.40 & 0.0645 & 0.0400 & 0.0989 & 0.0613 \\
\hline A13 & 149 & 71 & 29.50 & 18.35 & 0.0884 & 0.0608 & 0.1333 & 0.0899 \\
\hline A14 & 98 & 48 & 19.41 & 13.44 & 0.0675 & 0.0437 & 0.1004 & 0.0647 \\
\hline A15 & 176 & 93 & 34.85 & 24.03 & 0.1090 & 0.0757 & 0.1705 & 0.1133 \\
\hline Mean & 183.1 & 103.6 & 29.12 & 26.10 & 0.0848 & 0.0793 & 0.1299 & 0.1212 \\
\hline Species & 504 & 372 & 99.80 & 96.12 & 0.2017 & 0.2066 & 0.3273 & 0.3342 \\
\hline
\end{tabular}

For ISSR analysis, 372 polymorphic bands were detected using 15 ISSR primers. The PPB varied from $12.40 \%$ in the A12 population to $52.20 \%$ in the A2 population. The $H$ value varied from 0.0400 (A12) to 0.1511 (A2). The $I$ values ranged from 0.0631 (A12) to 0.1548 (A2). At the species level, the $H$ and $I$ values were 0.2066 and 0.3342 , respectively. Among the 15 populations, both SRAP and ISSR analyses indicated the highest levels of genetic diversity in the A5 and A2 populations, and the lowest levels in the A7 and A12 populations.

\section{Population genetic differentiation and gene flow}

Genetic diversity parameters at the species and population levels are shown in Table 5. For SRAP and ISSR analysis, the $H$ values were 0.0848 and 0.0793 within populations $\left(H_{\mathrm{S}}\right)$, and at the species level $\left(H_{\mathrm{T}}\right)$ they were 0.2017 and 0.2066 , respectively. The $I$ values were 0.1299 and 0.1175 at the population level $\left(H_{\mathrm{POP}}\right)$, and at the species level $\left(H_{\mathrm{SP}}\right)$ they were 0.3273 and 0.3342 , respectively. 
Table 5. Genetic differentiation within and among populations of Stipa bungeana by sequence-related amplified polymorphism (SRAP) and inter-simple sequence repeat (ISSR) analyses.

\begin{tabular}{lccccc}
\hline Genetic diversity parameters & \multicolumn{2}{c}{ Nei's gene diversity } & Genetic diversity parameters & \multicolumn{2}{c}{ Shannon's information index } \\
\cline { 2 - 3 } & SRAP & ISSR & & SRAP & ISSR \\
\hline$H_{\mathrm{S}}$ & 0.0848 & 0.0793 & $H_{\mathrm{POP}}$ & 0.1299 & 0.1175 \\
$H_{\mathrm{T}}$ & 0.2017 & 0.2066 & $H_{\mathrm{SP}}$ & 0.3273 & 0.3342 \\
$H_{\mathrm{S}} / H_{\mathrm{T}}$ & 0.4204 & 0.3838 & $H_{\mathrm{POP}} / H_{\mathrm{SP}}$ & 0.3969 & 0.3516 \\
$G_{\mathrm{ST}}$ & 0.5798 & 0.6160 & $\left(H_{\mathrm{SP}}-H_{\mathrm{POP}}\right) / H_{\mathrm{SP}}$ & 0.6031 & 0.6484 \\
$N_{\mathrm{M}}$ & 0.3623 & 0.3117 & & & \\
\hline
\end{tabular}

POPGENE 1.32 was used to analyze genetic differentiation from SRAP and ISSR data. For the SRAP analysis, $57.98 \%$ of genetic variation existed among populations and $41.02 \%$ of the genetic variation was within populations. For ISSR analysis, the genetic variation among populations was $61.60 \%$ (Table 5). The level of gene flow $\left(N_{\mathrm{M}}\right)$ was estimated to be 0.3623 individuals per generation among populations (Table 5). The results of ISSR were similar to results of SRAP, with $G_{\mathrm{ST}}=0.6160, N_{\mathrm{M}}=0.3117$, and $\left(H_{\mathrm{SP}}-H_{\mathrm{POP}}\right) / H_{\mathrm{SP}}=0.6484$. Both SRAP and ISSR analyses indicated high inter-population genetic differentiation and moderate intra-population genetic differentiation.

Genetic identity (I) and genetic distance (D) may be used to further illustrate the degree of genetic differentiation (Wang et al., 2011). According to the Mantel test, there was a significant correlation between the I values generated by the two marker systems $(r=0.6241$, $\mathrm{P}=0.001)$. Therefore, POPGENE 1.32 was used to calculate $\mathrm{D}$ values among the populations using combined SRAP and ISSR markers (Table 6). Based on the results of two markers, the I values of the 15 populations of $S$. bungeana ranged from 0.7613 (between A8 and A14) to 0.9870 (between A3 and A4), with a mean of 0.8749 . The D values varied from 0.0192 (between A14 and A15) to 0.2882 (between A8 and A12), with a mean of 0.1365 .

\begin{tabular}{|c|c|c|c|c|c|c|c|c|c|c|c|c|c|c|c|}
\hline Groups & $\mathrm{A} 1$ & $\mathrm{~A} 2$ & A3 & A4 & A5 & A6 & A7 & A8 & A9 & A 10 & A11 & A 12 & A 13 & A14 & A 15 \\
\hline A1 & 0 & 0.906 & 0.825 & 0.824 & 0.844 & 0.816 & 0.825 & 0.8 & 0.876 & 0.819 & 0.825 & 0.785 & 0.838 & 0.793 & 0.835 \\
\hline A2 & 0.099 & 0 & 0.955 & 0.946 & 0.952 & 0.93 & 0.868 & 0.848 & 0.927 & 0.87 & 0.875 & 0.83 & 0.895 & 0.839 & 0.884 \\
\hline A3 & 0.192 & 0.047 & 0 & 0.987 & 0.956 & 0.937 & 0.816 & 0.804 & 0.874 & 0.829 & 0.832 & 0.789 & 0.844 & 0.793 & 0.834 \\
\hline A4 & 0.193 & 0.056 & 0.013 & 0 & 0.968 & 0.95 & 0.815 & 0.802 & 0.872 & 0.822 & 0.825 & 0.782 & 0.843 & 0.788 & 0.829 \\
\hline A5 & 0.17 & 0.049 & 0.045 & 0.033 & 0 & 0.979 & 0.836 & 0.822 & 0.892 & 0.836 & 0.838 & 0.794 & 0.864 & 0.803 & 0.845 \\
\hline A6 & 0.203 & 0.072 & 0.065 & 0.051 & 0.022 & 0 & 0.802 & 0.792 & 0.86 & 0.808 & 0.809 & 0.769 & 0.832 & 0.777 & 0.816 \\
\hline A7 & 0.192 & 0.142 & 0.204 & 0.205 & 0.179 & 0.22 & 0 & 0.801 & 0.874 & 0.818 & 0.823 & 0.784 & 0.847 & 0.798 & 0.839 \\
\hline A8 & 0.223 & 0.165 & 0.218 & 0.221 & 0.196 & 0.233 & 0.222 & 0 & 0.864 & 0.794 & 0.792 & 0.75 & 0.816 & 0.761 & 0.801 \\
\hline A9 & 0.132 & 0.076 & 0.135 & 0.137 & 0.115 & 0.151 & 0.135 & 0.146 & 0 & 0.906 & 0.91 & 0.872 & 0.91 & 0.881 & 0.926 \\
\hline A10 & 0.2 & 0.139 & 0.187 & 0.196 & 0.18 & 0.214 & 0.201 & 0.231 & 0.099 & 0 & 0.979 & 0.967 & 0.869 & 0.946 & 0.957 \\
\hline A11 & 0.192 & 0.133 & 0.184 & 0.192 & 0.177 & 0.212 & 0.195 & 0.234 & 0.094 & 0.022 & 0 & 0.978 & 0.875 & 0.956 & 0.965 \\
\hline A12 & 0.242 & 0.186 & 0.238 & 0.246 & 0.23 & 0.263 & 0.244 & 0.288 & 0.137 & 0.034 & 0.022 & 0 & 0.835 & 0.948 & 0.949 \\
\hline A13 & 0.177 & 0.111 & 0.17 & 0.171 & 0.146 & 0.184 & 0.167 & 0.203 & 0.094 & 0.14 & 0.134 & 0.18 & 0 & 0.847 & 0.886 \\
\hline A14 & 0.232 & 0.175 & 0.232 & 0.238 & 0.219 & 0.253 & 0.226 & 0.273 & 0.127 & 0.055 & 0.045 & 0.054 & 0.166 & 0 & 0.981 \\
\hline A15 & 0.181 & 0.123 & 0.182 & 0.188 & 0.168 & 0.203 & 0.175 & 0.222 & 0.077 & 0.044 & 0.036 & 0.053 & 0.121 & 0.019 & 0 \\
\hline
\end{tabular}

\section{Genetic relationships}

Genetic relationships among the populations were constructed by UPGMA cluster analysis based on Nei's unbiased genetic distance matrix using combined SRAP and ISSR markers 
(Figure 2). The A1, A2, A3, A4, A5, and A6 populations grouped together initially, then clustered with the A9, A10, A11, A12, A13, A14, and A15 populations, and lastly, they clustered with the A7 and A8 populations. The UPGMA dendrogram indicated that populations of $S$. bungeana clustered together randomly, and did not form clear geographical distributions.

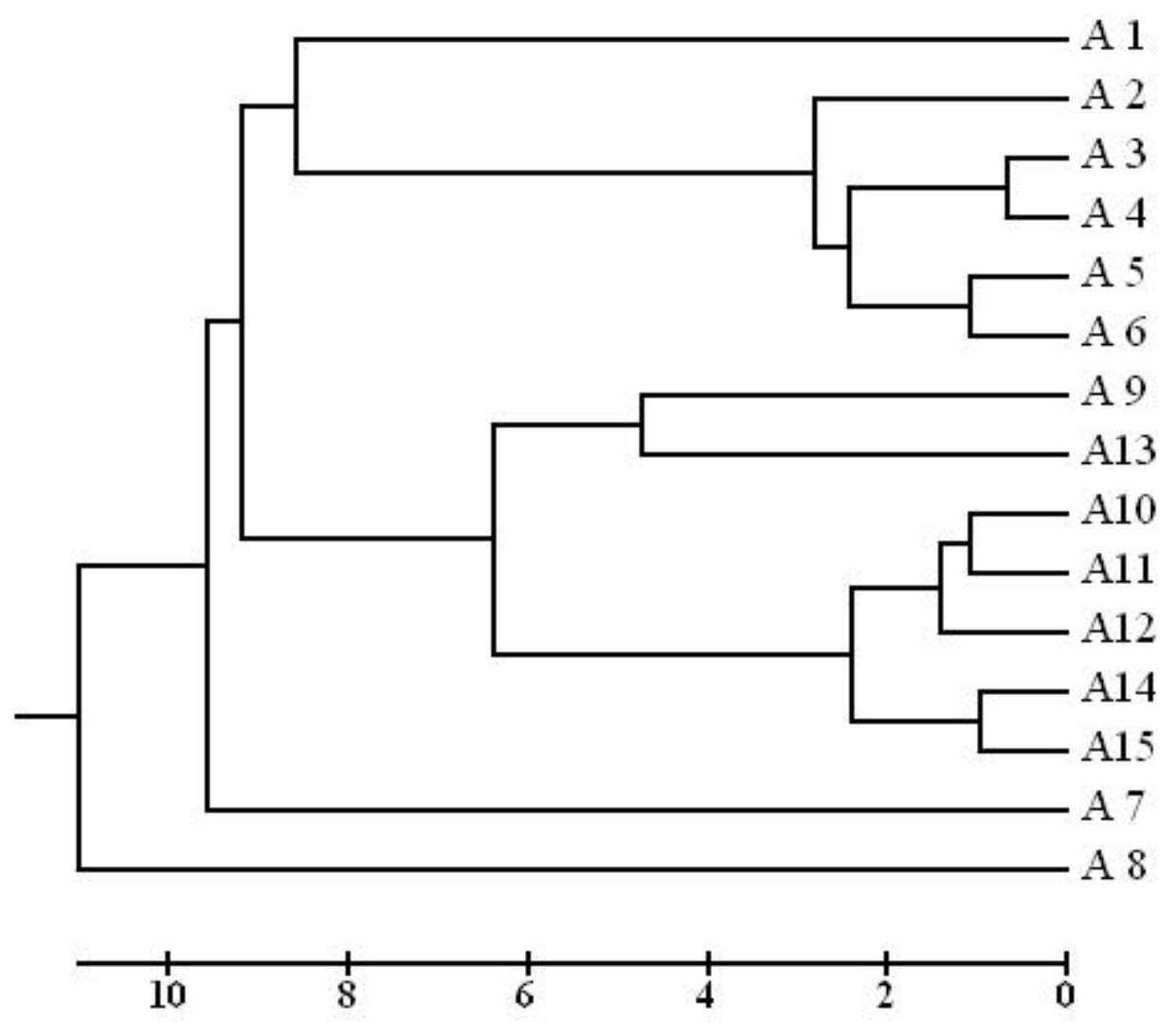

Figure 2. UPGMA dendrogram of Stipa bungeana populations based on SRAP and ISSR data.

The Mantel test performed using the $\mathrm{R}$ language showed a significant correlation between genetic distance and geographical distance $(r=0.3978, P=0.01)$ for the 15 populations.

\section{DISCUSSION}

\section{Genetic diversity of $S$. bungeana}

Genetic diversity refers to the level of genetic differentiation within a species. It also reflects the ability of a species to adapt to environmental changes and its potential for transformation and exploitation (Wang et al., 2011). Therefore, evaluation of genetic diversity is an essential component in germplasm characterization and collection (Wu et al., 2010a). Geographically isolated populations of plant species tend to accumulate genetic variations during 
the course of environmental adaptations (Sarwat et al., 2008). In the present study, based on ISSR markers, the $H$ value was 0.2066 and the $I$ value was 0.3342 at the species level. These results were higher than those obtained using SRAP markers $(H=0.2017, I=0.3273)$. Our results were similar to those of Song et al. (2010) who reported that SRAP markers only amplified target regions (the functional regions) of open reading frames, whereas ISSR markers are scattered throughout the genome, thus revealing the entire genomic diversity. Therefore, both ISSR and SRAP markers were effective and reliable for the accurate assessment of genetic variability of $S$. bungeana.

Compared with $S$. grandis $(H=0.1952, I=0.3035)$ (Wu et al., 2010a), our study revealed a relatively high level of genetic diversity $(H=0.2017, I=0.3273$, SRAP markers; and $H=0.2066, I=0.3342$, ISSR markers) in $S$. bungeana. One reason may be that the $S$. grandis populations were close to each other within a typical steppe, whereas our populations were collected from four provinces and different steppes. However, the observed genetic diversity was lower than that reported for $S$. krylovii $(H=0.2392, I=0.3818)$ (Wang et al., 2006) and $S$. purpurea $(H=0.2204, I=0.3517)$ (Liu et al., 2009). The genetic diversity was also lower than the reported values for long-lived perennial species $(H=0.25, \mathrm{~N}=37)$ and widespread species $(H=0.22, \mathrm{~N}=20)(\mathrm{Nybom}, 2004)$. Sun (1996) showed that the scope of a population has significant relevance to its genetic diversity. The lower genetic diversity of $S$. bungeana may be caused by human activities, such as diverse land use and the fragmented habitat formed in the Loess Plateau of China.

During the field survey and sampling, we found that the populations with low genetic diversity were located near human residential areas or traffic arteries. In contrast, populations with high genetic diversity were located far from residential areas. These areas have favorable environmental conditions, little human disturbance, and the populations are large. Genetic theory indicates that genetic variation levels are positively correlated with effective population size (Frankham, 1996). In addition, larger and older populations often have higher intra-population genetic variation than do younger populations (Hamrick and Godt, 1996). Therefore, we suggest that the low level of human disturbance and large effective population size have led to relatively higher genetic diversity in S. bungeana.

\section{Population genetic structure of $S$. bungeana}

Population genetic structure is defined as the nonrandom distribution pattern of genetic variation of one species or population in space and time. To a large extent, it represents the evolutionary potential of a species or population (Sun, 1996). Genetic differentiation and gene flow are important indices for assessing the population genetic structure of a species. In the present study, the values of $G_{\mathrm{ST}}$ for $S$. bungeana were 0.5798 and 0.6160 based on the SRAP and ISSR markers, which were higher than the values reported for long-lived perennial species $\left(\Phi_{\mathrm{ST}}=\right.$ $0.25, \mathrm{~N}=60)$, out-crossing species $\left(\Phi_{\mathrm{ST}}=0.25, \mathrm{~N}=73\right)$, mixed breeding species $\left(\Phi_{\mathrm{ST}}=0.40, \mathrm{~N}\right.$ $=18)$, and widespread species $\left(\Phi_{\mathrm{ST}}=0.34, \mathrm{~N}=32\right)(\mathrm{Nybom}, 2004)$. Wright (1951) pointed out that genetic differentiation was strong when the coefficient was greater than 0.25 . Therefore, results of the present study showed that $S$. bungeana populations have high genetic differentiation.

Gene flow, the movement of genes within and among populations, is negatively correlated with genetic differentiation, and is essential for population transfer and plant evolution (Slatkin, 1985). Previous studies demonstrated that if $N_{\mathrm{M}}<1$, the rare communication among 
populations cannot compensate for the genetic diversity lost by genetic drift and inbreeding depression, both of which reduce genetic diversity within populations and eventually enhance genetic differentiation among populations (Slatkin, 1985; Apostol et al., 1996; Lenormand et al., 1998). In this study, the $N_{\mathrm{M}}$ values of $S$. bungeana were 0.3623 and 0.3117 using SRAP and ISSR markers, respectively. This level of migration will not prevent divergence among populations. Habitat fragmentation and diverse land use are factors that affect genetic structure, but further evidence is needed to explain whether these factors have had such an impact on the genetic structure of S. bungeana (Yu et al., 2012). In addition, Billings (1973) indicated that alpine plants are capable of asexual reproduction through clonal growth, which is considered to be the result of adaptation to the harsh conditions where pollinators are sparse and seedling survival is relatively low. In our study, the most adverse environmental condition is drought, and it is hard for seedlings to establish themselves in the Loess Plateau. The seed germination rate of $S$. bungeana is relatively low, and it grows mainly by clonal reproduction to expand the population. This special reproduction increases mating opportunities among similar individuals and blocks effective gene flow among different populations.

Hamrick and Godt (1989) reported that genetic distance among populations was correlated with geographical distance. However, our study showed the opposite trend. We found low levels of correlation between geographic and genetic distances after merging the SRAP and ISSR marker data $(\mathrm{r}=0.3978, \mathrm{P}=0.01)$. These results are similar to an analysis in Angiopteris chauliodonta Copel. in the Pitcairn islands (Kingston et al., 2004), for Rheum tanguticum Maxim. ex Balf. in China (Hu et al., 2010), and for Tetraena mongolica Maxim. in China (Ge et al., 2003), which indicated that geographical distance might not be the main factor affecting genetic differentiation among populations of S. bungeana. Volis et al. (2001) suggested that if natural selection was environmentally induced, the genetic similarity between population groups must reflect the similarity between their environments and must be independent of geographical distance. Therefore, we suggest that the correlation between geographical distance and genetic diversity cannot be a general rule; the link between different geomorphologic and historical situations to genetic diversity should be considered.

\section{Conservation considerations}

S. bungeana is one of the main wild forage plants in the grassland of northwest China. It is also important for controlling the loss of water and soil erosion in the Loess Plateau because of its fibrous roots and highly developed root system (Cheng et al., 2011). Wild invasion by exotic species and human disturbance have reduced and fragmented the population's habitats and driven the species toward extinction (Kölliker et al., 1998). If the environmental degradation caused by natural and human-induced factors exceeds the maximum limit, the result will be loss of genetic diversity for a species or population (Yan et al., 2010). Successful management and conservation of populations of endangered species rely on a good understanding of the distribution of genetic variation of the species. Our study provides important genetic information for developing collection strategies for S. bungeana.

The relatively low genetic diversity and limited gene flow of $S$. bungeana populations indicated an endangered status of $S$. bungeana under current conditions. Considering the intensive utilization and increased fragmentation of the $S$. bungeana-dominated steppe in the Loess Plateau, more rational land use practices should be adopted so that the grassland 
is conserved. If necessary, natural reserves of S. bungeana should be established, this could protect the species and its habitat, especially for the low genetic diversity populations. In addition, gene flow among populations could be improved by artificial means, such as deliberate pollination, extensive seed collection, distribution of seeds into different populations, and transplanting individuals from one habitat to another.

\section{ACKNOWLEDGMENTS}

Research supported by the Strategic Priority Research Program - Climate Change: Carbon Budget and Related Issues of the Chinese Academy of Sciences (\#XDA05050202), and the earmarked fund for Modern Agro-Industry Technology Research System (\#CARS-35-40).

\section{REFERENCES}

Apostol BL, Black WC, Reiter P and Miller BR (1996). Population genetics with RAPD-PCR markers: the breeding structure of Aedes aegypti in Puerto Rico. Heredity 76 (Pt 4): 325-334.

Billings WD (1973). Arctic and Alpine vegetations: similarities, differences, and susceptibility to disturbance. Bioscience 23: 697-704.

Budak H, Shearman RC, Parmaksiz I and Dweikat I (2004). Comparative analysis of seeded and vegetative biotype buffalograsses based on phylogenetic relationship using ISSRs, SSRs, RAPDs, and SRAPs. Theor. Appl. Genet. 109: 280-288.

Cheng J, Wu GL, Zhao LP, Li Y, et al. (2011). Cumulative effects of 20-year exclusion of livestock grazing on above- and belowground biomass of typical steppe communities in arid areas of the Loess Plateau, China. Plant Soil. Environ 57: 40-44.

Excoffier L, Smouse PE and Quattro JM (1992). Analysis of molecular variance inferred from metric distances among DNA haplotypes: application to human mitochondrial DNA restriction data. Genetics 131: 479-491.

Ferriol M, Pico B and Nuez F (2003). Genetic diversity of a germplasm collection of Cucurbita pepo using SRAP and AFLP markers. Theor. Appl. Genet. 107: 271-282.

Frankham R (1996). Relationship of genetic variation to population size in wildlife la relación entre la variacion genética y el tamaño poblacional en vida silvestre. Conserv. Biol. 10: 1500-1508.

Ge XJ, Yu Y, Zhao NX, Chen HS, et al. (2003). Genetic variation in the endangered Inner Mongolia endemic shrub Tetraena mongolica Maxim. (Zygophyllaceae). Biol. Conserv. 111: 427-434.

Godwin ID, Aitken EA and Smith LW (1997). Application of inter simple sequence repeat (ISSR) markers to plant genetics. Electrophoresis 18: 1524-1528.

Guo DL and Luo ZR (2006). Genetic relationships of some PCNA persimmons (Diospyros kaki Thunb.) from China and Japan revealed by SRAP analysis. Genet. Resour. Crop. Ev. 53: 1597-1603.

Hamrick JL and Godt MJW (1989). Allozyme Diversity in Plant Species. In: Plant Population Genetics, Breeding and Genetic Resources (Brown AHD, Clegg MT, Kahler AL and Weir BS, eds.). Sinauer Associates, Sunderland, 43-63.

Hamrick JL and Godt MJW (1996). Effects of life history traits on genetic diversity in plant species. Philos. T. Roy. Soc. B. 351: 1291-1298.

Hu Y, Wang L, Xie X, Yang J, et al. (2010). Genetic diversity of wild populations of Rheum tanguticum endemic to China as revealed by ISSR analysis. Biochem. Syst. Ecol. 38: 264-274.

Kingston N, Waldren S and Smyth N (2004). Conservation genetics and ecology of Angiopteris chauliodonta Copel. (Marattiaceae), a critically endangered fern from Pitcairn Island, South Central Pacific Ocean. Biol. Conserv. 117: 309-319.

Kölliker R, Stadelmann FJ, Reidy B and Nösberger J (1998). Fertilization and defoliation frequency affect genetic diversity of Festuca pratensis Huds. in permanent grasslands. Mol. Ecol. 7: 1557-1567.

Lenormand T, Guillemaud T, Bourguet D and Raymond M (1998). Evaluating gene flow using selected markers: a case study. Genetics 149: 1383-1392.

Li G and Quiros CF (2001). Sequence-related amplified polymorphism (SRAP), a new marker system based on a simple PCR reaction: its application to mapping and gene tagging in Brassica. Theor. Appl. Genet. 103: 455-461.

Liu WS, Dong M, Song ZP and Wei W (2009). Genetic diversity pattern of Stipa purpurea populations in the hinterland of Qinghai-Tibet Plateau. Ann. App. Biol. 154: 57-65. 
Mantel N (1967). The detection of disease clustering and a generalized regression approach. Cancer Res. 27: 209-220. McDermott JM and McDonald BA (1993). Gene flow in plant pathosystems. Annu. Rev. Phytopathol. 31: 353-373.

Nybom H (2004). Comparison of different nuclear DNA markers for estimating intraspecific genetic diversity in plants. Mol. Ecol. 13: 1143-1155.

Rohlf FJ (2000). NTSYS-pc: Numerical Taxonomy and Multivariate Analysis System, Version 2.1. Exeter Software, New York.

Sarwat M, Das S and Srivastava PS (2008). Analysis of genetic diversity through AFLP, SAMPL, ISSR and RAPD markers in Tribulus terrestris, a medicinal herb. Plant Cell Rep. 27: 519-528.

Shao QS, Guo QS, Deng YM and Guo HP (2010). A comparative analysis of genetic diversity in medicinal Chrysanthemum morifolium based on morphology, ISSR and SRAP markers. Biochem. Syst. Ecol. 38: 1160-1169.

Slatkin M (1985). Gene flow in natural populations. Annu. Rev. Ecol. Syst. 16: 393-430.

Song Z, Li X, Wang H and Wang J (2010). Genetic diversity and population structure of Salvia miltiorrhiza Bge in China revealed by ISSR and SRAP. Genetica 138: 241-249.

Sun M (1996). Effects of population size, mating system, and evolutionary origin on genetic diversity in Spiranthes sinensis and S. hongkongensis. Conserv. Biol. 10: 785-795.

Volis S, Yakubov B, Shulgina I, Ward D, et al. (2001). Tests for adaptive RAPD variation in population genetic structure of wild barley, Hordeum spontaneum Koch. Biol. J. Linn. Soc. 74: 289-303.

Wang DN, Mu CC, Gao Z and Feng FJ (2011). ISSR analysis of genetic diversity of Juglans mandshurica Maxim populations. Nonwood Forest Res. 29: 22-29.

Wang JL, Zhao NX, Gao YB, Lin F, et al. (2006). RAPD analysis of genetic diversity and population genetic structure of Stipa krylovii Reshov. in Inner Mongolia steppe. Genetika 42: 587-594.

Wright S (1951). The genetical structure of populations. Ann. Eugen. 15: 323-354.

Wu JB, Gao YB, Bao XY, Gao H, et al. (2010a). Genetic diversity of Stipa grandis P. Smirn populations across the species' range in the Inner Mongolia Plateau of China. Biochem. Syst. Ecol. 38: 471-477.

Wu YG, Guo QS, He JC, Lin YF, et al. (2010b). Genetic diversity analysis among and within populations of Pogostemon cablin from China with ISSR and SRAP markers. Biochem. Syst. Ecol. 38: -63.

Yan JJ, Bai SQ, Zhang XQ, Chang D, et al. (2010). Genetic diversity of native Elymus sibiricus populations in the Southeastern Margin of Qinghai-Tibetan Plateau as detected by SRAP and SSR marker. Acta Pratacult. Sin. 19: 122-134.

Yeh FC and Boyle TJB (1997). Population genetic analysis of co-dominant and dominant markers and quantitative traits. Belg. J. Bot. 129: 157.

Yu J, Jing ZB and Cheng JM (2012). Genetic diversity of Stipa bungeana populations in the Loess Plateau of China using inter-simple sequence repeat (ISSR) markers. Afr. J. Biotechnol. 11: 8425-8432.

Zhang FM and Song GE (2002). Data analysis in population genetics. I. Analysis of RAPD data with AMOVA. Biodiversity Sci. 10: 438-444.

Zhao NX, Gao YB, Wang JL, Ren AZ, et al. (2006). RAPD diversity of Stipa grandis populations and its relationship with some ecological factors. Acta Ecol. Sin. 26: 1312-1318.

Zhao NX, Gao YB, Wang JL and Ren AZ (2008). Population structure and genetic diversity of Stipa grandis P. Smirn, a dominant species in the typical steppe of northern China. Bioch. Syst. Ecol. 36: 1-10. 